http://dx.doi.org/10.1021/ja102129c

This document is the unedited author's version of a Submitted Work that was subsequently accepted for publication in The Journal of the American Chemical Society, copyright $($ American Chemical Society after peer review.

To access the final edited and published work, see http://pubs.acs.org/articlesonrequest/AOR-ffRktq44n73F9AsqbW3u 


\title{
An Alternative Approach to Aldol Reactions: Gold-Catalysed Formation of Boron Enolates from Alkynes
}

\author{
Cindy Körner, Pavel Starkov, and Tom D. Sheppard* \\ Department of Chemistry, University College London, \\ Christopher Ingold Laboratories, 20 Gordon St, London, WC1H OAJ, UK.
}

RECEIVED DATE (automatically inserted by publisher); tom.sheppard@ucl.ac.uk

The aldol reaction is one of the most well established and widely used methods for the formation of carbon-carbon bonds. ${ }^{1}$ However, without natural substrate bias, the chemoselective formation of an enolate from one carbonyl component in the presence of another is extremely challenging. Therefore, the most commonly employed solution is the use of a preformed enolate or enolate equivalent. ${ }^{2} \mathrm{~A}$ method for the direct generation of an enolate from a non-carbonyl precursor would provide a more elegant approach, but such methods are rare and generally incompatible with the presence of enolisable aldehydes. ${ }^{3}$ In this communication, we describe the first catalytic method for the generation of enolates from unactivated alkynes. The conditions are extremely mild and the enolate can be generated even in the presence of aldehydes prone to selfcondensation.

We envisaged that a boron enolate could be obtained by the goldcatalysed $^{4}$ addition of a boronic acid to an alkyne. ${ }^{5}$ In order to demonstrate this concept, we prepared ortho-alkynylbenzene boronic acid 1a in two steps from bromoiodobenzene. ${ }^{6}$ Treatment of 1a with $2 \mathrm{~mol} \% \mathrm{PPh}_{3} \mathrm{AuNTf}_{2}{ }^{7}$ led to the rapid formation of isolable boron enolate $2\left(\mathrm{R}^{1}=\mathrm{Bu}\right)^{8}$ in $85 \%$ yield (Scheme 1). There was no evidence for the formation of products via 5-exo dig cyclisation in contrast to the Au-catalysed cyclisation of the corresponding carboxylic acids. ${ }^{9}$ Selective formation of the 6-membered ring in our case may be due to possible aromatic stabilization present in $\mathbf{2} .{ }^{8}$ Boron enolate $\mathbf{2}$ underwent aldol reaction with butyraldehyde at room temperature to give the cyclic boronate 3a as a mixture of separable diastereoisomers. Gratifyingly, in a one-pot procedure where the boron enolate was generated in the presence of the aldehyde, the aldol product 3a was obtained in $87 \%$ isolated yield (80:20 dr) over two steps.

Scheme 1 Gold catalysed boron enolate formation/aldol reaction.

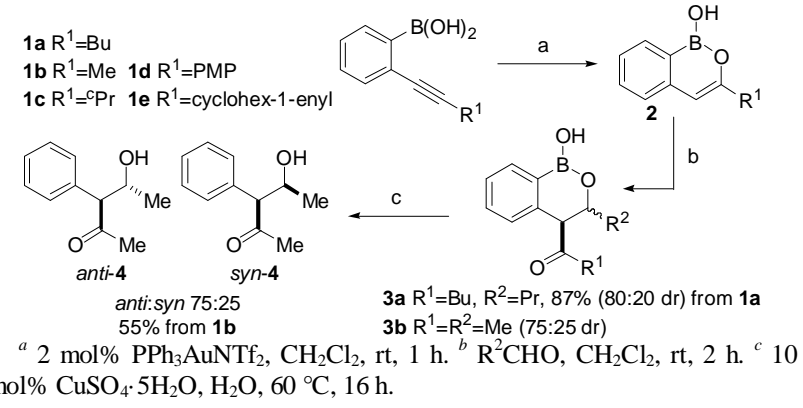

In order to determine the stereochemistry of the products, we then prepared cyclic boronate $\mathbf{3 b}(75: 25 \mathrm{dr})$, which underwent protodeborylation to give the known alcohols 4 (75:25 dr). ${ }^{10}$ The major diastereoisomer was found to be anti-4, derived from trans3b. Careful comparison of the ${ }^{1} \mathrm{H}$ NMR spectra of the cyclic boronate $\mathbf{3 a}$ with that of $\mathbf{3 b}$ indicated that trans-3a was the major product in the reaction of boronic acid $\mathbf{1 a} .^{11}$

The one-pot enolate formation/aldol reaction was found to be applicable to a range of alkynes and aldehydes (Scheme 2 and Table 1). The mild enolate formation conditions were even compatible with acetaldehyde which is prone to self-condensation in the presence of acid or base. ${ }^{12}$ In some cases, the cyclic boronates $\mathbf{3 a}-\mathbf{i}$ were prone to retro-aldol reaction and could not be isolated via chromatography. However, the cyclic boronate provides a useful handle for further transformations, and the crude reaction products could be used directly in subsequent steps. Multi-step sequences were developed for direct conversion of the boronic acids 1a-e into phenols/acetates (5 or 6), biaryls (7) and 2,3-dihydrobenzofurans ${ }^{13}$ (8) via oxidation, ${ }^{14}$ Suzuki-Miyaura coupling ${ }^{15}$ or Chan-Lam coupling, ${ }^{16}$ respectively. These latter reactions are the first examples of intramolecular Chan-Lam coupling reactions ${ }^{17}$ employing aliphatic alcohols. ${ }^{18}$ Excellent isolated yields of the final products were obtained over two or three steps. In each case, the diastereoisomers were assigned by comparison of the ${ }^{1} \mathrm{H}$ NMR spectra of the cyclic boronates $\mathbf{3 c}-\mathbf{i}$ with 3a-b. ${ }^{11}$ Importantly, no change in diastereomeric ratio was observed during the post-aldol transformations.

Scheme 2 Transformation of aldol products 3 via oxidation, Suzuki reaction or Chan-Lam coupling.

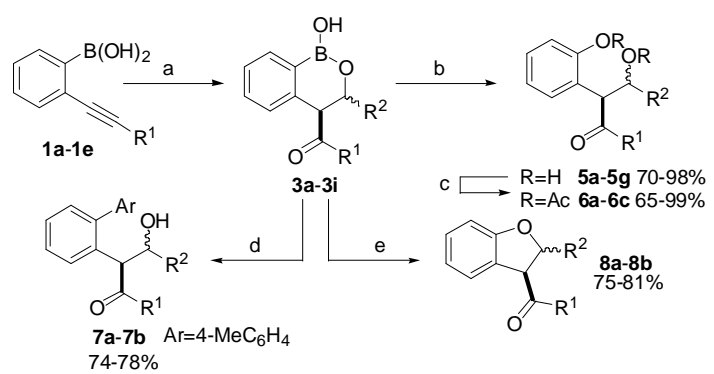

${ }^{a} 1-2$ mol$\% \mathrm{PPh}_{3} \mathrm{AuNTf}_{2}, \mathrm{R}^{2} \mathrm{CHO}, \mathrm{CH}_{2} \mathrm{Cl}_{2}$, rt, 1-12 h. ${ }^{b} \mathrm{mCPBA}, \mathrm{CH}_{2} \mathrm{Cl}_{2}$, rt, 30 min. ${ }^{c} \mathrm{Ac}_{2} \mathrm{O}$, pyridine, rt, 2 h. ${ }^{d} 3 \mathrm{~mol} \%\left(\mathrm{PPh}_{3}\right)_{2} \mathrm{PdCl}_{2}, \mathrm{CsF}$, ArI, $\mathrm{CH}_{2} \mathrm{Cl}_{2}, 37^{\circ} \mathrm{C}, 10 \mathrm{~h} .{ }^{e} 5 \mathrm{~mol} \% \mathrm{Cu}(\mathrm{OAc})_{2} \cdot \mathrm{H}_{2} \mathrm{O}, \mathrm{MeOH}, 40^{\circ} \mathrm{C}, 10 \mathrm{~h}$.

Table 1 Gold-catalysed enolate formation/aldol reactions followed by oxidation, Suzuki-Miyaura or Chan-Lam coupling

\begin{tabular}{|lc|c|c|}
\hline & Isolated Yield $^{\mathrm{b}}$ & anti:syn $^{\text {Product }^{\mathrm{a}}}$ \\
\hline & $\mathbf{5 a}$ & $91 \%$ & $80: 20$ \\
\hline & $\mathbf{5 b}$ & $97 \%$ & \\
\hline
\end{tabular}




\begin{tabular}{|l|l|l|}
\hline & & \\
\hline
\end{tabular}

The above reactions demonstrate that the gold-catalysed addition of a boronic acid to an alkyne is a feasible method for accessing boron enolates for use in aldol reactions. We were also keen to explore intermolecular boron enolate formation as this would allow the use of catalytic quantities of boronic acid. Pleasingly, on stirring aldehyde $9^{19}$ (Scheme 6) with 2 mol\% $\mathrm{PPh}_{3} \mathrm{AuNTf}_{2}$ and $30 \mathrm{~mol} \%$ of commercially available boronic acid 10, a slow reaction took place over the course of three days to give enone $\mathbf{1 1}^{20}$ as the sole product in $50 \%$ isolated yield. In this case, as expected, complete selectivity for Markovnikov addition of the boronic acid to the alkyne is observed.

Scheme 3 Combined $\mathrm{Au} / \mathrm{ArB}(\mathrm{OH})_{2}$ catalysed aldol condensation.

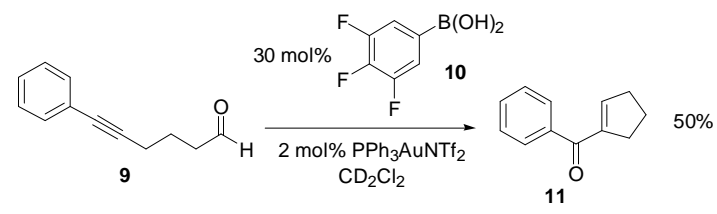

Enone 11 could potentially be produced via a gold-catalysed alkyne-carbonyl metathesis, analogous to reported Ag-catalysed reactions. ${ }^{21}$ However, in the absence of the arylboronic acid $\mathbf{1 0}$ no reaction occurred with the gold catalyst over a similar time period, providing evidence to support the intermediacy of a boron enolate.

In summary, we have developed an efficient catalytic method for generating boron enolates from unactivated alkynes. The enolate formation is exceptionally mild and the enolates can be trapped by aldehydes present in the reaction mixture. Intramolecular enolate formation/aldol reactions provide access to a range of functionalised scaffolds in excellent yield, after subsequent transformation of the boronic acid. We have also demonstrated the feasibility of a combined gold/boronic acid catalysed aldol condensation reaction. Further work is underway to explore the scope of this novel approach to enolate chemistry.
Acknowledgments. We are grateful to Dr. Abil Aliev (UCL) for technical assistance with the NMR studies. Financial support for this work was provided by the EPSRC (Advanced Research Fellowship to T.D.S. and a PhD studentship to P.S.), and the DAAD (scholarship to C.K.).

Supporting Information Available: Detailed experimental procedures and characterization of all new compounds. This material is available free of charge via the Internet at http://pubs.acs.org.

1. Modern Aldol Reactions; Mahrwald, R., Evans, D. A., Eds; WILEYVCH, Weinheim, 2004; Vol. 1-2.

2. (a) Mahrwald, R. Chem. Rev. 1999, 99, 1095. (b) Cowden, C. J.; Paterson, I. in Organic Reactions Vol. 51, pp 1-200.

3. (a) Gazzard, L. J.; Motherwell, W. B.; Sandham, D. A. J. Chem. Soc., Perkin Trans. I 1999, 979. (b) Cuperly, D.; Petrignet, J.; Crevisy, C.; Gree, R. Chem. Eur. J. 2006, 12, 3261.

4. (a) Hoffmann-Röder, A.; Krause, N. Org. Biomol. Chem. 2005, 3, 387. (b) Zhang, L.; Sun, J.; Kozmin, A. S. Adv. Synth. Catal. 2006, 348 , 2271. (c) Hashmi, A. S. K.; Hutchings, G. J. Angew. Chem. Int. Ed. 2271. (c) Hashmi, A. S. K.; Hutchings, G. J. Angew. Chem. Int. Ed. 2007, 46, 3410. (e) Jiménez-Núñez, E.; Echavarren, A. M. Chem. Commun. 2007, 333. (f) Gorin, D. J.; Toste, F. D. Nature 2007, 446, 395. (g) Hashmi, A. S. K. Chem. Rev. 2007, 107, 3180. (h) Skouta, R.; Li, C. -J. Tetrahedron 2008, 64, 4917. (i) Shen, H. C. Tetrahedron 2008, 64, 3885. (j) Shen, H. C. Tetrahedron 2008, 64, 7847. (k) Li, Z.; Brouwer, C.; He, C. Chem. Rev. 2008, 108, 3239.

5. For mercury-mediated addition of $\mathrm{Ph}_{2} \mathrm{BOH}$ to ethoxyacetylene see: Murakami, M.; Mukaiyama, T. Chem. Lett. 1982, 241.

6. (a) Odedra, A.; Wu, C. -J.; Pratap, T. B.; Huang, C. -W.; Ran, Y. -F.; Liu, R. -S. J. Am. Chem. Soc. 2005, 127, 3406. (b) Brown, H. C.; Cole, T. E. Organometallics 1983, 2, 1316.

7. Mézailles, N.; Ricard, L.; Gagosz, F. Org. Lett. 2005, 7, 4133.

8. (a) Greig, L. M.; Kariuki, B. M.; Habershon, S.; Spencer, N.; Johnston, R. L.; Harris, K. D. M.; Philp, D. New J. Chem. 2002, 26, 701. (b) Arcus, V. L.; Main, L.; Nicholson, B. K. J. Organomet. Chem. 1993, 460, 139. (c) Letsinger, R. L.; Nazy, J. R. J. Am. Chem. Soc. 1959, 81, 3013. (d) Chen, J.; Bajko, Z.; Kampf, J. W.; Ashe III, A. J. Organometallics 2007, 26, 1563.

9. (a) Marchal, E.; Uriac, P.; Legouin, B.; Toupet, L.; van de Weghe, P. Tetrahedron 2007, 63, 9979. (b) Aikawa, H.; Tago, S.; Umetsu, K.; Haginiwa, N.; Asao, N. Tetrahedron 2009, 65, 1774.

10. Mukaiyama, T.; Banno, K.; Narasaka, K. J. Am. Chem. Soc. 1974, 96, 7503.

11. See supporting information for details

12. For recent catalytic reactions of acetaldehyde see: (a) Hayashi, Y.; Itoh, T.; Ohkubo, M.; Ishikawa, H. Angew. Chem. Int. Ed. 2008, 47, 4722. (b) Yang, J. W.; Chandler, C.; Stadler, M.; Kampen, D.; List, B. Nature 2008, 452, 453 .

13. For a recent approach to dihydrobenzofurans see: Coy B., E. D.; Jovanovic, L.; Sefkow, M. Org. Lett. 2010, DOI: 10.1021/ol100433z.

14. Falck, J. R.; Bondlela, M.; Venkataraman, S. K.; Srinivas, D. J. Org. Chem. 2001, 66, 7148

15. Kotha, S.; Lahiri, K.; Kashinath, D. Tetrahedron 2002, 58, 9633.

16. (a) Chan, D. M. T.; Monaco, K. L.; Wang, R. -P.; Winters, M. P. Tetrahedron Lett. 1998, 39, 2933. (b) Evans, D. A.; Katz, J. L.; West, T. R. Tetrahedron Lett 1998, 39, 2937. (c) Lam, P. Y S. Clark, C. G. Saubern, S.; Adams, J.; Winters, M. P. Chan, D M. T.; Combs, A. Tetrahedron Lett. 1998, 39, 2941. (d) King, A. E.; Brunold, T. C.; Stahl, S. S. J. Am. Chem. Soc. 2009, 131, 5044 .

17. Decicco, C. P.; Song, Y.; Evans, D. A. Org. Lett. 2001, 3, 1029.

18. (a) Quach, T. D.; Batey, R. A. Org. Lett. 2003, 5, 1381. (b) Shade, R. E.; Hyde, A. M.; Olsen, J. -C.; Merlic, C. A. J. Am. Chem. Soc. 2010, 132,1202 .

19. (a) Roesch, K. R.; Larock, R. C. J. Org. Chem. 2001, 66, 412. (b) Lin, G. -Y.; Yang, C. -Y.; Liu, R. -S. J. Org. Chem. 2007, 72, 6753.

20. Satoh, T.; Itaya, T.; Okuro, K.; Miura, M.; Nomura, M. J. Org. Chem. 1995, 60, 7267.

21. Rhee, J. U.; Krische, M. J. Org. Lett. 2005, 7, 2493. 


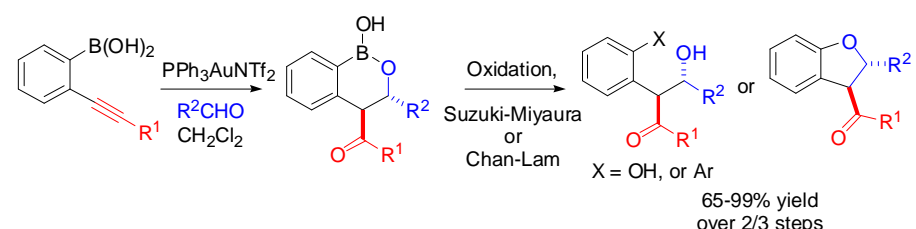

A new method for enolate generation via the gold-catalysed addition of boronic acids to alkynes is reported. The formation of boron enolates from readily accessible ortho-alkynylbenzeneboronic acids proceeds rapidly with $2 \mathrm{~mol}_{\%} \mathrm{PPh}_{3} \mathrm{AuNTf}_{2}$ at ambient temperature. The enolates undergo aldol reaction with an aldehyde present in the reaction mixture to give cyclic boronate esters, which can be subsequently transformed into phenols, biaryls or dihydrobenzofurans via oxidation, SuzukiMiyaura or intramolecular Chan-Lam coupling respectively. A combined gold/boronic acid catalysed aldol condensation reaction of an alkynyl aldehyde was also successfully achieved. 